\title{
Formação docente: o contexto de pandemia COVID-19 e a atuação docente universitária no Brasil
}

\author{
Teacher training: the context of the COVID-19 pandemic and university teaching activities in
} Brazil

Formación docente: el contexto de la pandemia COVID-19 y las actividades docentes universitarias en Brasil

\section{Resumo}

A pandemia causada pelo novo coronavírus afetou a sociedade em diversos aspectos. No que diz respeito ao ensino e a necessidade de adequação às recomendações das organizações de saúde, as instituições buscaram nas estratégias de atividades educacionais remotas, uma alternativa para manter seus alunos em atividades acadêmicas. Objetivou-se com a revisão integrativa descrever os desafios e as possibilidades encontrados pelos educadores no processo ensino aprendizagem e a didática no espaço virtual nessa mudança emergencial. A pesquisa foi realizada nas bases de dados eletrônicas Scielo, Periódicos Capes e Biblioteca Virtual em Saúde (BVS) na busca por publicações em formato de artigos, compreendendo o período de 2020 a 2021, considerando os seguintes descritores: "ensino superior" "COVID19" "ensino online" "docente" e aplicando critérios de inclusão e exclusão.Foram encontrados 56 artigos (n=56), que foram reduzidos para $(n=13)$ após análise. Os dados demonstram que a corrida para garantir a continuidade do ensino e a ausência de capacitação e formação continuada para manejo das tecnologias digitais resultaram na promoção de aulas remotas nos mais variados níveis e apesar dos esforços, o ensino remoto emergencial trouxe implicações negativas no processo de ensino-aprendizagem. No entanto, alguns trabalhos demonstram que quando se tem o 
conhecimento sobre a ferramenta é possível aumentar o engajamento dos alunos nas aulas.Esperamos contribuir tanto na reflexão crítica acerca da formação continuada de professores do ensino superior como fomentar as discussões da integração das TDIC aos currículos do Ensino Superior presencial.

Palavras-chave: Educação; Ensino superior; Pandemia; COVID-19.

\begin{abstract}
The pandemic caused by the new coronavirus has affected society in several ways. With regard to teaching and the need to adapt to the recommendations of health organizations, institutions sought remote educational activities strategies, an alternative to keep their students in academic activities. The objective was an integrative review defining the challenges and possibilities found by educators in the teaching-learning process and didactics in the virtual space in this emergency change. The research was carried out in the Scielo, Capes Periodicals and Virtual Health Library (VHL) electronic databases, searching for publications in article format, covering the period from 2020 to 2021 , considering the descriptors: "higher education" "COVID-19" "online teaching" "teacher" and applying inclusion and exclusion criteria.56 articles $(n=56)$ were found, which were reduced to $(n=13)$ after analysis. The data report that the race to ensure the continuity of education and the lack of training and continuing education for the management of digital technologies resulted in the promotion of remote classes at various levels and despite efforts, emergency remote teaching brought negative implications in the process of teaching-learning. However, some works report that when you have knowledge about the tool, it is possible to increase student engagement in classes. We hope to contribute both to the critical reflection on the continuing education of higher education teachers and to foster discussions on the integration of TDIC into the curriculum on Higher Education.
\end{abstract}

Keywords: Education; Higher education; Pandemic; COVID-19.

\title{
Resumen
}

La pandemia provocada por el nuevo coronavirus ha afectado a la sociedad de varias formas. En cuanto a la docencia y la necesidad de adaptarse a las recomendaciones de las organizaciones de salud, las instituciones buscaron en las estrategias de actividades educativas a distancia, una alternativa para mantener a sus estudiantes en las actividades académicas. El objetivo fue una revisión integradora definiendo los desafíos y posibilidades que encuentran los educadores en el proceso de enseñanza-aprendizaje y la didáctica en el espacio virtual en este cambio de emergencia. La investigación se realizó en las bases de datos electrónicas Scielo, Capes Periodicals y Virtual Health Library (VHL) en la búsqueda de publicaciones en formato de artículo, cubriendo el período de 2020 a 2021, considerando los siguientes descriptores: "educación superior" "COVID-19" "docencia online" "docente" y aplicando criterios de inclusión y exclusión. Se encontraron 56 artículos $(n=56)$, que se redujeron a $(n=13)$ después del análisis. Los datos demuestran que la carrera por asegurar la continuidad de la educación y la falta de formación y educación continua para el manejo de las tecnologías digitales resultó en la promoción de clases a distancia en varios niveles y a pesar de los esfuerzos, la enseñanza a distancia de emergencia trajo implicaciones negativas en el proceso de enseñanzaaprendizaje. Sin embargo, algunos trabajos demuestran que cuando se tiene conocimiento sobre la herramienta, es posible incrementar la participación de los estudiantes en las clases. Esperamos contribuir tanto a la reflexión crítica sobre la formación continua de los profesores de educación superior como a fomentar debates sobre la integración del TDIC en los planes de estudio de la educación superior presencial.

Palabras clave: Educación; Enseñanza superior; Pandemia; COVID-19.

\section{Introdução}

O ano de 2020 teve seu início marcado pelo surto da doença causada pelo novo coronavírus, COVID-19. Em janeiro de 2020 era uma emergência de saúde pública de importância internacional, e em março foi declarada a pandemia afetando vários países e regiões do mundo (OPAS/OMS, 2020). Dentre as medidas de prevenção de contaminação está o distanciamento social, com decretos de fechamento de comércios, escolas e universidades, dentre outras situações de aglomeração.

Esse cenário trouxe reflexões sobre os métodos de ensino na impossibilidade da realização de aulas presenciais. No Brasil, em março de 2020, foi publicada a portaria 544 do Ministério da Educação, a qual: "Dispõe sobre a substituição das aulas presenciais por aulas em meios digitais enquanto durar a situação de pandemia do Novo Coronavírus - COVID -19”. Exigindo criação de novos caminhos para dar seguimento às aulas e expôs uma deficiência de formação na cibercultura e Tecnologias de Informação e Comunicação (TIC’s) acumulada e negligenciada na formação docente.

As universidades precisaram ser repensadas no que diz respeito à estrutura dos seus processos e práticas comunicativas. Se até agora elas tinham se estruturado como focos difusores de conhecimento na forma unidirecional, ou seja, de um para muitos, o contexto da pandemia COVID-19 alterou a dinâmica e levou as instituições educacionais a adaptarem 
novos modelos pedagógicos e inclusão de tecnologias para produção de conhecimentos transdisciplinares e com isso apresentou-se de forma evidente a problemática sobre a formação de formadores e seu exercício docente com as novas demandas sociais, culturais, pedagógicas e políticas da cibercultura (Santos et al., 2021; Santos, Martins, 2015). A cibercultura incorpora o conjunto de ferramentas e sistemas computacionais, mas também, as práticas, atitudes, pensamentos e valores das comunidades que a criaram e que convivem nesta rede (Santos, Cardim, 2016).

A capacitação docente é um dos principais fatores que podem promover a qualidade do ensino, mesmo em condições adversas (Gusso et al., 2020). No contexto da pandemia os docentes vivenciaram a construção dos saberes pedagógicos a partir da capacidade de investigar sua própria atividade como docente e ressignificá-la para auxiliar seu saber-fazer, ficando claro a necessidade de atualização dos conhecimentos e competências profissionais, os quais não se resumem, apenas, ao domínio do conteúdo a ser ministrado para o aluno, mas envolvem também o aprender e o uso de TIC's de forma significativa para o processo de ensino-aprendizagem. (Santos Junior, Monteiro, 2020).

A docência é uma atividade complexa e desafiadora, exigindo do professor uma constante disposição para aprender, questionar e investigar sobre como e por que ensinar. Além das mudanças constantes da sociedade, o cenário pandêmico trouxe mais mudanças no âmbito da educação. O objetivo deste trabalho é analisar por meio da revisão integrativa os desafios e as possibilidades encontrados pelos educadores nesse processo de mudança emergencial e compreender como se apresenta a didática no espaço virtual e suas relações com os processos de ensino e aprendizagem e as diversas tecnologias aplicadas no ensino de diferentes áreas de conhecimento, durante a pandemia do COVID-19.

\section{Metodologia}

O presente estudo trata-se de uma revisão integrativa sobre a formação docente na cibercultura e utilização de tecnologia nas atividades de ensino na pandemia do COVID-19. Por conceito, revisão integrativa refere-se a um estudo bibliográfico, de natureza qualitativa em que há interpretação por parte do pesquisador e opiniões sobre o fenômeno em estudo (Pereira et al., 2018) e com técnicas e etapas pré-definidas, sujeitas a reprodução (Rother, 2007) e análise de informações científicas, com vista a identificar omissões de conhecimento, apontar estudos já produzidos e indicar prioridades para futuros estudos e/ou tomada de decisões (Paiva et al., 2016). Para Botelho et al., (2011), a revisão integrativa é constituída de seis fases e que utilizamos na elaboração deste artigo, são elas: identificação do tema e a pergunta guia da pesquisa, escolha de critérios de inclusão e exclusão, identificação dos estudos pré-selecionados, categorização destes estudos, análise e interpretação dos resultados e a apresentação da síntese-revisão do conhecimento.

A partir da definição do problema a ser estudado a pergunta norteadora utilizada neste estudo foi: Quais os desafios e as possibilidades encontrados pelos educadores nesse processo de mudança emergencial? Pesquisamos artigos nas bases de dados eletrônicas Scielo, Periódicos Capes e Biblioteca Virtual em Saúde (BVS), utilizando descritores em saúde e aplicando critérios de inclusão e exclusão. A busca ocorreu com a utilização dos descritores "ensino superior", "COVID-19”, "ensino online", "docente" em combinação e através da leitura dos resumos e palavras chaves dos artigos na base de dados, foram organizados para a seleção dos estudos a serem incluídos pesquisas que abordassem a temática, publicadas em formato de artigos, compreendendo o período de 2020 a 2021 que estivessem indexados nas bases de dados mencionadas.

A revisão foi restrita a artigos que abordam os desafios dos professores no ensino durante a pandemia e o uso de tecnologias aplicadas ao ensino superior em diversas áreas do conhecimento no Brasil. Foram excluídos os artigos que não correspondiam ao interesse de pesquisa, estudos de revisão, artigos com duplicidade de dados; títulos e/ou resumos que não atendiam aos critérios de inclusão foram excluídos, bem como trabalhos com ausência de informações pertinentes.

Após a leitura e análise dos artigos selecionados os resultados obtidos foram colocados em uma tabela de revisão integrativa detalhando de forma clara e objetiva os dados mais relevantes encontrados na seleção dos artigos e ao final a 
proposição de propostas para pesquisas futuras.

\section{Resultados}

De um total de 292 documentos identificados, excluindo-se os artigos duplicados (25) iniciou-se a etapa de triagem, onde após a leitura e análise do título e resumo de cada

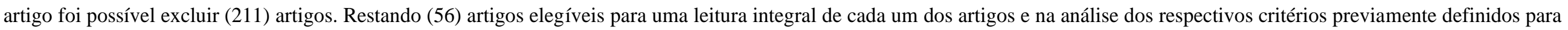

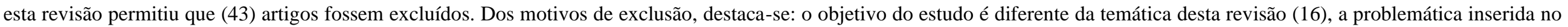

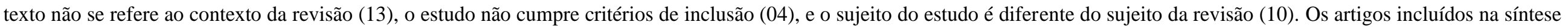
qualitativa a serem trabalhados em nossa temática ficaram representados em número de (13) artigos.

Os resultados da revisão integrativa obtidos no estudo foram analisados e colocados de forma explicativa apresentada na Quadro 1, onde se tem detalhado os autores e o ano de

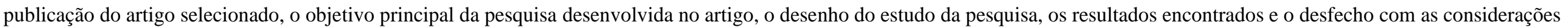
finais.

Quadro 1 - Resultados obtidos da revisão integrativa.

\begin{tabular}{|c|c|c|c|c|}
\hline Autor/Ano & Objetivo & Tipo de estudo & Resultados & Desfecho \\
\hline Bastos et al., 2020 & $\begin{array}{l}\text { Descrever a experiência no ensino remoto emergencial para } \\
\text { as aulas teóricas na graduação em Enfermagem em } \\
\text { decorrência da COVID-19. }\end{array}$ & Relato de experiência & $\begin{array}{l}\text { O relato revelou que o processo de ensino remoto } \\
\text { emergencial das aulas teóricas na graduação em } \\
\text { Enfermagem por conta da pandemia da COVID-19 } \\
\text { perpassou pela capacitação docente sobre as } \\
\text { tecnologias virtuais utilizadas, assim como a } \\
\text { necessidade de aproximar a relação educador- } \\
\text { educando, mesmo diante do afastamento, com } \\
\text { vistas a favorecer esse processo. }\end{array}$ & $\begin{array}{l}\text { De modo geral, a experiência } \\
\text { favoreceu a aquisição de } \\
\text { conhecimentos com plataformas } \\
\text { virtuais com a implantação de aulas e } \\
\text { treinamento dos docentes nesse } \\
\text { processo. }\end{array}$ \\
\hline Dosea et., 2020 & $\begin{array}{l}\text { Analisar a opinião de universitários acerca dos métodos } \\
\text { ativos de aprendizagem no ensino on-line }\end{array}$ & Estudo qualitativo & $\begin{array}{l}\text { Para os estudantes é possível manter o método ativo } \\
\text { como recurso de ensino/aprendizagem na aula on- } \\
\text { line; consideraram que a aprendizagem com método } \\
\text { ativo na modalidade on-line foi relevante; avaliaram } \\
\text { que as propostas de aula executadas pelos } \\
\text { professores proporcionaram um conteúdo que foi } \\
\text { apreendido de maneira efetiva. No entanto, apesar } \\
\text { deste resultado, foi evidente que os estudantes }\end{array}$ & $\begin{array}{l}\text { Os acadêmicos entrevistados avaliam } \\
\text { o aprendizado na aula remota como } \\
\text { relevante, possibilitando ainda um } \\
\text { contexto de estudo pautado no } \\
\text { método ativo. Entretanto, há } \\
\text { interferências que influenciam } \\
\text { negativamente no desenvolvimento } \\
\text { do acadêmico, representando assim }\end{array}$ \\
\hline
\end{tabular}




\begin{tabular}{|c|c|c|c|c|}
\hline & & & $\begin{array}{l}\text { apresentam algumas problemáticas que influenciam } \\
\text { negativamente na qualidade da experiência } \\
\text { vivenciada na aula on-line. }\end{array}$ & $\begin{array}{l}\text { um desafio para promoção de um } \\
\text { processo de ensino e aprendizagem } \\
\text { que atenda às necessidades desse } \\
\text { público. }\end{array}$ \\
\hline Maciel et al., 2020 & $\begin{array}{l}\text { Relatar a experiência do processo de adaptação ao ensino } \\
\text { remoto em uma instituição de ensino superior em } \\
\text { enfermagem que utiliza exclusivamente a metodologia ativa, } \\
\text { Aprendizagem Baseada em Problemas. }\end{array}$ & Relato de experiência & $\begin{array}{l}\text { Dentre as fortalezas foi evidenciado o planejamento } \\
\text { de ensino adequado às atividades remotas, } \\
\text { capacitação, suporte tecnológico e agilidade. Além } \\
\text { da experiência prévia dos docentes e discentes com } \\
\text { plataformas digitais. Quanto às fragilidades, foi } \\
\text { constatada a baixa qualidade da internet, da minoria } \\
\text { dos participantes. }\end{array}$ & $\begin{array}{l}\text { A utilização da metodologia proposta } \\
\text { apresentou-se de maneira efetiva. O } \\
\text { processo de adaptação docente foi } \\
\text { favorecido pela organização e } \\
\text { extenso apoio institucional, por meio } \\
\text { das coordenações diretas de cada } \\
\text { curso, equipe de tecnologia e do } \\
\text { EAD, não havendo grandes } \\
\text { limitações. }\end{array}$ \\
\hline $\begin{array}{l}\text { Ferreira, Branchi \& } \\
\text { Sugahara, } 2020\end{array}$ & $\begin{array}{l}\text { Descrever o uso de plataformas digitais no ensino remoto em } \\
\text { uma Instituição de Ensino Superior do Estado de São Paulo, } \\
\text { em cursos administrados com metodologia tradicional e com } \\
\text { metodologias ativas, durante a pandemia Covid-19. }\end{array}$ & Relato de experiência & $\begin{array}{l}\text { Inicialmente algumas dificuldades ocorreram com a } \\
\text { utilização das ferramentas. Foi necessários um } \\
\text { esforço e uma busca para fazer bom uso das } \\
\text { ferramentas disponibilizadas. Esse desafio foi } \\
\text { superado uma vez que a Instituição de Ensino } \\
\text { Superior, diante dessa realidade, planejou a } \\
\text { capacitação aos docentes em ferramentas diversas. }\end{array}$ & $\begin{array}{l}\text { As atividades realizadas } \\
\text { remotamente permitiram } \\
\text { oportunidades de aprendizado para } \\
\text { os docentes e discentes e contaram } \\
\text { com o apoio da IES para superar os } \\
\text { obstáculos encontrados. }\end{array}$ \\
\hline $\begin{array}{l}\text { Barbosa, Viegas, } \\
\text { Batista (2020) }\end{array}$ & $\begin{array}{l}\text { Analisar e apresentar os dados obtidos sobre os impactos } \\
\text { identificados e relatados pelos profissionais de } \\
\text { educação do ensino superior,do município do Rio de Janeiro, } \\
\text { mediante isolamento social, sobre suas experiências do novo } \\
\text { modelo de aula proposto pelas instituições. }\end{array}$ & $\begin{array}{l}\text { Estudo quali- } \\
\text { quantitativo }\end{array}$ & $\begin{array}{l}\text { A maior parte conhecia o conceito de ensino } \\
\text { híbrido, mas não possuíam habilidade com a } \\
\text { ferramenta. Uma parcela expressiva dentro da } \\
\text { amostra, não foi dado um treinamento básico. } \\
\text { Houve uma boa realização das tarefas e atividades } \\
\text { conforme o planejado. Porém, não eficaz, a } \\
\text { considerar que não houve uma totalidade de alunos } \\
\text { com acesso ao ensino/aprendizagem, fator que } \\
\text { compromete a qualidade da prestação de serviço } \\
\text { das IES públicas e privadas. }\end{array}$ & $\begin{array}{l}\text { Com falta de capacitação além de } \\
\text { não atingir os objetivos no processo } \\
\text { ensino/aprendizado, o profissional de } \\
\text { educação pode ser acometido por } \\
\text { uma outra problemática, a frustração } \\
\text { do não conhecimento e domínio } \\
\text { pleno da ferramenta, ampliando sua } \\
\text { carga horária de trabalho em busca } \\
\text { dessa competência. }\end{array}$ \\
\hline $\begin{array}{l}\text { Schleich, Pinto, } \\
2021\end{array}$ & $\begin{array}{l}\text { Expor, sob o ponto de vista de profissionais da educação, a } \\
\text { avaliação da ferramenta criada para prover capacitação } \\
\text { rápida e acessível em métodos e linguagens digitais para } \\
\text { professores em âmbito nacional. }\end{array}$ & $\begin{array}{l}\text { Estudo quali- } \\
\text { quantitativo }\end{array}$ & $\begin{array}{l}\text { Os dados obtidos a partir desta pesquisa } \\
\text { demonstraram uma taxa de retenção de concluintes } \\
\text { que gira em torno do dobro da média nacional para } \\
\text { cursos a distância em geral. A massiva preferência }\end{array}$ & $\begin{array}{l}\text { Os feedbacks positivos indicam que } \\
\text { as estratégias de gamificação } \\
\text { possuem potencial relevante, como } \\
\text { ferramenta, para aumentar o }\end{array}$ \\
\hline
\end{tabular}




\begin{tabular}{|c|c|c|c|c|}
\hline & & & $\begin{array}{l}\text { dos participantes por treinamentos gamificados em } \\
\text { detrimento de treinamentos tradicionais on-line } \\
\text { após a realização do curso-jogo, aliada à } \\
\text { discriminação de que a metodologia seja nova e } \\
\text { inovadora, reforça a necessidade de busca por } \\
\text { estratégias ativas de ensino na abordagem digital. }\end{array}$ & $\begin{array}{l}\text { engajamento, especialmente quando } \\
\text { utilizadas de forma adequada ao } \\
\text { público que se pretende atingir. }\end{array}$ \\
\hline $\begin{array}{l}\text { Espíndola,Nóbrega, } \\
\text { Ramos, } 2020\end{array}$ & $\begin{array}{l}\text { Apresentar o processo de pesquisa, desenvolvimento e } \\
\text { avaliação de uma iniciativa de formação docente para } \\
\text { professores que atuavam no curso de licenciatura em ciências } \\
\text { biológicas, modalidade semipresencial da Universidade } \\
\text { Federal de Santa Catarina (UFSC), Brasil. }\end{array}$ & 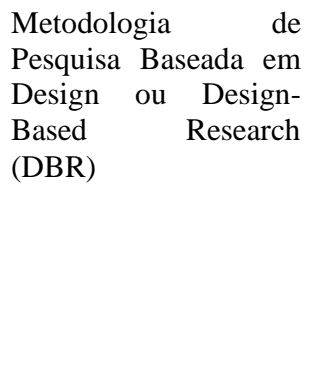 & $\begin{array}{l}\text { Permitiu-se a experimentação de ferramentas } \\
\text { vinculada às discussões sobre o ensino das } \\
\text { disciplinas, oferecendo a possibilidade de superar a } \\
\text { visão instrumental dos meios tecnológicos. A } \\
\text { integração de TDIC não se reduz à seleção e uso de } \\
\text { recursos tecnológicos, mas se concretiza a partir de } \\
\text { um processo de articulação das potencialidades } \\
\text { destas ferramentas aos conhecimentos e saberes dos } \\
\text { professores no desenvolvimento de possibilidades } \\
\text { educativas para seus contextos de ensino. }\end{array}$ & $\begin{array}{l}\text { Foi possível promover discussões } \\
\text { com os professores em contextos de } \\
\text { ensino mediado pelas TDIC sobre os } \\
\text { conteúdos de ciências e biologia e } \\
\text { suas pedagogias e também sobre as } \\
\text { tecnologias, suas relações com as } \\
\text { ciências e a biologia e suas } \\
\text { potencialidades pedagógicas. }\end{array}$ \\
\hline Diniz, Silva, 2020 & $\begin{array}{l}\text { Analisar os desafios, as possibilidades e as dificuldades do } \\
\text { curso de licenciatura em Geografia (campus Araguaína) em } \\
\text { propor ações formativas e de acolhimento para seus (suas) } \\
\text { discentes }\end{array}$ & $\begin{array}{l}\text { Estudo quali- } \\
\text { quantitativo }\end{array}$ & $\begin{array}{l}\text { A proposta de manter o manter contato, } \\
\text { acolhimento e ações que visam efetivar o processo } \\
\text { de formação docente de modo remoto on-line } \\
\text { mostrou-se condicionada a limitações de ordem } \\
\text { tecnológica e de um contexto social inédito e ainda } \\
\text { enigmático }\end{array}$ & $\begin{array}{l}\text { O trabalho trouxe reflexões no } \\
\text { campo educacional do ensino } \\
\text { superior no período pandêmico, em } \\
\text { especial para os cursos de formação } \\
\text { de professores de Geografia, abrindo } \\
\text { espaço para outras interlocuções em } \\
\text { tempos tão atípicos e desafiantes, } \\
\text { que nos fazem (re)pensar e } \\
\text { (re)significar as práticas docentes e } \\
\text { de pesquisa. }\end{array}$ \\
\hline $\begin{array}{l}\text { Schmitt, Bugalho, } \\
\text { Kruger, } 2021\end{array}$ & $\begin{array}{l}\text { Identificar as principais estratégias do processo de ensino- } \\
\text { aprendizagem, bem como as percepções dos docentes } \\
\text { durante o período de isolamento social no contexto da } \\
\text { pandemia gerada pela Covid-19 }\end{array}$ & $\begin{array}{l}\text { Estudo quali- } \\
\text { quantitativo }\end{array}$ & $\begin{array}{l}\text { As disciplinas ocorreram de forma remota; e } 76 \% \\
\text { responderam que a instituição ofereceu capacitação. } \\
\text { Os docentes que utilizaram r de } \\
\text { problematização/casos de ensino, debates e uso de } \\
\text { jogos, acreditam ter } \\
\text { ensino-aprendizagem. }\end{array}$ & $\begin{array}{l}\text { De forma geral, os resultados } \\
\text { demonstram adaptação das aulas } \\
\text { presenciais ao formato remoto, bem } \\
\text { como os achados sugerem a } \\
\text { importância da inserção das } \\
\text { tecnologias como estratégias de } \\
\text { ensino, independentemente de o } \\
\text { modelo ser ou não presencial. }\end{array}$ \\
\hline Ferreira et al., 2020 & $\begin{array}{l}\text { Refletir sobre a formação continuada dos professores e a } \\
\text { incorporação das tecnologias digitais para o uso nas práticas } \\
\text { pedagógicas remotas desenvolvidas no contexto da pandemia }\end{array}$ & Relato de experiência & $\begin{array}{l}\text { Pensar a atuação do professor neste momento de } \\
\text { transição do ensino presencial para o ensino remoto } \\
\text { emergencial e a falta de formação continuada desse }\end{array}$ & $\begin{array}{l}\text { Perante o referido cenário, pouco se } \\
\text { tem ponderado sobre a formação } \\
\text { continuada do professor e o }\end{array}$ \\
\hline
\end{tabular}


Research, Society and Development, v. 10, n. 12, e43101320800, 2021

(CC BY 4.0) | ISSN 2525-3409 | DOI: http://dx.doi.org/10.33448/rsd-v10i13.20800

\begin{tabular}{|c|c|c|c|c|}
\hline & de Covid-19. & & $\begin{array}{l}\text { profissional impacta nos dilemas contemporâneos } \\
\text { do uso obrigatório e urgente das interfaces digitais, } \\
\text { em caráter instrumentalista, a fim de manter os } \\
\text { vínculos entre docentes e discentes e dar } \\
\text { continuidade ao calendário letivo nas instituições. }\end{array}$ & $\begin{array}{l}\text { redirecionamento de suas práticas } \\
\text { com a utilização das tecnologias } \\
\text { digitais como interface essencial para } \\
\text { essa conjuntura. }\end{array}$ \\
\hline $\begin{array}{l}\text { Sallaberry et al., } \\
2020\end{array}$ & $\begin{array}{l}\text { Investigar os efeitos do isolamento social nas dificuldades } \\
\text { enfrentadas pelos docentes dos cursos de Ciências Contábeis } \\
\text { de instituições de ensino superior públicas e privadas. }\end{array}$ & Estudo qualitativo & $\begin{array}{l}\text { Os respondentes tiveram uma redução da sua } \\
\text { mobilidade, no entanto houve uma disponibilidade } \\
\text { de tempo também foi reduzida, principalmente por } \\
\text { conta da necessidade de ajuste e preparação de } \\
\text { novos materiais para as classes virtuais. }\end{array}$ & $\begin{array}{l}\text { Evidenciou-se a adaptabilidade dos } \\
\text { docentes em relação às dificuldades } \\
\text { já enfrentadas antes da pandemia, } \\
\text { bem como implicações que podem } \\
\text { colaborar para a adoção de } \\
\text { estratégias de adequação do processo } \\
\text { de ensino. }\end{array}$ \\
\hline $\begin{array}{l}\text { Ries, Rocha, Silva. } \\
2020\end{array}$ & $\begin{array}{l}\text { Avaliar o ensino remoto de Epidemiologia para cursos da } \\
\text { área da saúde de instituição pública }\end{array}$ & $\begin{array}{l}\text { Estudo quali- } \\
\text { quantitativo }\end{array}$ & $\begin{array}{l}\text { O conjunto de resultados mostrou a } \\
\text { potencialidade de ensino e aprendizagem e } \\
\text { possibilitou adequações na continuidade } \\
\text { disciplinas considerando as limitações da } \\
\text { modalidade identificadas pelos participantes }\end{array}$ & $\begin{array}{l}\text { Pode-se pontuar a importância da } \\
\text { fluência tecnológica pelo professor, e } \\
\text { da necessidade de se utilizar modelos } \\
\text { mais dinâmicos de ensino e } \\
\begin{array}{lll}\text { aprendizagem, comor as } \\
\text { metodologias ativas. }\end{array}\end{array}$ \\
\hline Galvão et al., 2021 & $\begin{array}{l}\text { Investigou a incorporação das tecnologias de informação e } \\
\text { comunicação (TIC) no processo de ensino-aprendizagem por } \\
\text { professores, graduandos e pós-graduandos em Enfermagem, } \\
\text { de instituições de ensino públicas e privadas brasileiras, antes } \\
\text { e durante a pandemia. }\end{array}$ & $\begin{array}{l}\text { Estudo quali- } \\
\text { quantitativo }\end{array}$ & $\begin{array}{l}\text { Apesar do ensino remoto ter sido iniciado em } \\
\text { caráter emergencial no Brasil, pode-se observar que } \\
\text { alunos de graduação, alunos de pós-graduação e } \\
\text { docentes da Enfermagem se mobilizaram para dar } \\
\text { continuidade às atividades e empregaram as TIC's } \\
\text { nesse processo, com alguma diferença a depender } \\
\text { da região do país em que estavam. }\end{array}$ & $\begin{array}{l}\text { Não é suficiente a maioria ter acesso } \\
\text { às TIC's e às condições adequadas } \\
\text { para a participação no ensino remoto. } \\
\text { Se um discente ou um docente não } \\
\text { possuir as mesmas oportunidades, } \\
\text { todo o processo fica eticamente } \\
\text { comprometido. }\end{array}$ \\
\hline
\end{tabular}

Fonte: Autores. 


\section{Discussão}

Os recursos digitais são todo e qualquer dispositivo ou mídia digital, disponível online, isto é, na rede mundial de internet ou offline a partir de diversos suportes digitais como tablets, celulares, laptops, aparelhos de TV, os quais podem ser acessados independentemente de conexão com a internet. São recursos digitais programas, plataformas virtuais, aplicativos, jogos, harwares e softwares, portais e sites da internet, câmeras, entre outros. Todos eles podem ser inseridos no contexto educacional, configurando-se um recurso pedagógico digital (Nonato, Sales, Cavalcante, 2021).

No entanto, o recurso pedagógico é muito mais que a materialidade do recurso em si. Recurso é um meio para uma solução, uma ajuda para resolver um problema dado. Para ser caracterizado como recurso pedagógico, é necessário que possua características ou atenda a objetivos educativos de trabalho com conteúdos educativos e situações de formação. Para distinguir um recurso pedagógico de quaisquer outros recursos, deve-se ter como referência a ação do professor ao planejar, ao delimitar objetivos pedagógicos para o trabalho com conteúdos e atitudes educativas (Nonato, Sales, Cavalcante, 2021).

No contexto da educação a distância $(\mathrm{EaD})$ observa-se o planejamento e uso de estratégias de gerenciamento específicos dos recursos digitais além da oferta de uma estrutura informacional adequada, suporte técnico aos professores e estudantes, cuidadosa elaboração e entrega de materiais didáticos a serem utilizados nas aulas, bem como apoio pedagógico aos estudantes e treinamento contínuo em tecnologia aos professores (Gusso et al., 2020). Ao contrário das experiências planejadas para ofertar EaD, no contexto de pandemia da Covid-19, o modo de oferta improvisado das disciplinas curriculares pelas Instituições de Ensino Superior (IES) têm sido designado como Ensino Remoto Emergencial, ou seja, uma mudança temporária de ensino para um modo de ensino alternativo devido às circunstâncias de crise, neste caso envolve o uso de soluções de ensino totalmente remotas para instrução ou educação que, de outra forma, seriam ministradas presencialmente ou como cursos combinados ou híbridos (Hodges et al., 2020).

Com a necessidade das aulas unicamente mediadas por tecnologias, inicia-se uma corrida para garantir a continuidade do ensino. Estas medidas resultaram na promoção de aulas remotas nos mais variados níveis, os professores em decorrência dessa transição das aulas presenciais para o ensino remoto de forma abrupta (Schmidt, Lopes, Pereira, 2020).

A atuação docente para o exercício no ensino superior perpassa mais que um título de mestrado e/ou doutorado (Moran 2013). É necessário uma formação pedagógica que articule o conhecimento científico com o didático, para que esse profissional, a partir da reflexão, se sobressaia com êxito, tanto nas questões impostas pela instituição como nas que se vinculam à realidade social (Corrêa, Ribeiro, 2013). No cenário pandêmico destacou-se outros entraves articulados a essa formação, como a utilização das mídias digitais sem capacitação devida, apesar de estarmos inseridos em um mundo envolvido pelo uso intenso das tecnologias digitais, como demonstrado nos resultados de nossa pesquisa.

A capacitação dos professores envolve, por exemplo, prepará-los para: adequar condições e estratégias de ensino ao ambiente on-line; promover a participação dos estudantes on-line; manejar adequadamente o sistema on-line e o software do curso; e identificar o que fazer e a quem recorrer quando ocorrerem certos problemas de tecnologia (Gusso et al., 2020).

Os trabalhos encontrados nesta pesquisa evidenciam a importância da capacitação dos professores e do planejamento para a utilização das ferramentas disponíveis, os desafios e as possibilidades no ensino emergencial remoto. O trabalho de Bastos et al. (2020) traz a experiência do ensino emergencial na graduação de enfermagem e aponta para a imprescindibilidade do processo de capacitação para utilização dos ambientes virtuais, coloca discussões acerca do distanciamento educadoreducando como sendo um dos nós críticos do processo pedagógico. Entretanto, afirma que esse afastamento transcende o estar perto, pois o ser humano tende conscientemente a distanciar-se das pessoas para se fazer presente e coloca que nesse sentido, o manejo hábil das plataformas virtuais pelos docentes deve ser considerado estratégia essencial para minimizar o impacto nesse processo de interação, pois sua implementação traz múltiplas possibilidades de comunicação interpessoal, trabalho 
colaborativo, criação de exercícios de avaliação e auto avaliação, acesso ao processamento de informações, interação, gestão e administração educativa pelos discentes que se constrói de maneira horizontal do conhecimento em detrimento de práticas culturais e educacionais rígidas

Para Bastos et al. (2020) é importante que os discentes estejam inteirados sobre o uso da plataforma. Especificamente para os discentes de Enfermagem do estudo não houve necessidade de um treinamento repentino, uma vez que já são ambientados com tais plataformas, pois no Projeto Pedagógico do Curso existe a previsão de 18\% das disciplinas disponíveis na modalidade EAD. Mesmo diante desse fato, foi dada atenção pela coordenação no sentido de sanar dúvidas existentes, além de ter sido oferecido um tutorial específico para os discentes.

Dosea et al. (2020) discutiu sobre as fragilidades do ensino remoto. Para os autores, há fatores limitantes como a falta de acesso à internet, a instabilidade do sinal Wi-Fi, a ausência de recursos tecnológicos (smartphone, notebook, tablet entre outros), qualidade da transmissão da aula, a facilidade para a distração do aluno e a ergonomia, relacionada ao ambiente de estudo. Os autores afirmam também que estes são fatores que possuem relação com o processo de aprendizagem do acadêmico, isto é, à medida que as situações complicadoras aumentam, a satisfação dos alunos diminui, reduzindo assim a participação desses discentes nas discussões durante a aula remota

Ainda no trabalho de Dosea et al. (2020) outro fator considerado como um desafio para o ensino remoto é a dificuldade para manusear as ferramentas do ambiente virtual em que o estudante está inserido, decorrente frequentemente da carência ou inexistência de capacitação ofertada pelas instituições de ensino para os usuários, ou mesmo por falhas de funcionamento da plataforma.

Maciel et al. (2020) trouxe o relato do uso de metodologias ativas no ensino remoto em um curso superior de enfermagem. $\mathrm{Na}$ instituição em questão, os docentes já tinham contato prévio e diário com tecnologias digitais, tanto relacionadas a questões operacionais como registro de notas e e-mail institucional, como direcionado para educação, por meio do ambiente virtual de aprendizagem utilizado como ferramenta de apoio aos grupos tutoriais. Assim, o estímulo ao uso de tecnologias e inclusão digital dos docentes faz-se presente na instituição em diversos cenários.

A plataforma escolhida pela instituição estudada por Maciel et al. (2020), havia sido utilizada anteriormente para educação continuada dos docentes. Fato que grande parte dos docentes já tinha um contato prévio, facilitando o processo de adaptação inicial. Entretanto, algumas funções como o compartilhamento de arquivos e questões operacionais eram novidade para os docentes. A fim de otimizar a adaptação docente a esta ferramenta, as equipes de tecnologia e Ensino à Distância (EAD) criaram vídeos tutoriais lúdicos e autoexplicativos sobre o uso da plataforma que foram disponibilizados para todos os docentes e discentes. Também foi oferecido suporte individualizado a fim de sanar eventuais dúvidas operacionais. A estrutura tecnológica e o preparo das equipes envolvidas foram pontos fortes no processo de adaptação aos recursos tecnológicos. Para os autores o aprendizado online de qualidade resulta de planejamento e designer instrucional cuidadoso. Sendo o principal ponto a ser considerado nessa adaptação emergencial, o pouco tempo para planejamento.

No trabalho de Ferreira,Branchi,Sugahara (2020) evidenciou-se que no caso da Instituição de Ensino Superior, objeto de estudo, inicialmente algumas dificuldades ocorreram com a utilização das ferramentas para atividades de ensino e avaliação e das normalmente usadas para facilitar as reuniões. A necessidade de adaptação e reformulação das aulas e o contato com os alunos nas plataformas virtuais foi bastante dificultoso e demandou grande tempo de dedicação para se apropriar e buscar fazer bom uso das ferramentas disponibilizadas. Entretanto, o ambiente colaborativo que ocorreu entre alunos, entre alunos e professores, entre professores, entre professores e gestores e entre gestores, contribuiu para o aprendizado sobre as ferramentas e trocas de experiências entre os envolvidos. Esse desafio foi superado uma vez que a Instituição de Ensino Superior, diante dessa realidade, planejou a capacitação aos docentes em ferramentas diversas.

Para Ferreira,Branchi,Sugahara (2020) um outro desafio para os professores além da utilização das ferramentas é a 
organização do tempo destinado às atividades remotas. Isso envolve maior disponibilidade dos professores para atender às demandas dos alunos (respostas das dúvidas por e-mail no período extraclasse), e maior tempo dispensado para correções de trabalhos entregues para convalidar presença dos alunos e para preparação de avaliações criativas com várias versões de questões pela plataforma.

No trabalho de Barbosa, Viegas, Batista (2020) a principal problemática apresentada em relação às aulas remotas, diz respeito às propostas metodológicas de interação do professor com o aluno, através de chats, foruns, salas de tarefas sem o devido treinamento,no qual a experiência de aprendizagem neste modelo remoto envolve as instituições de ensino, equipes pedagógicas, docentes e discentes, todos vivenciando algo novo e de forma repentina. Com esse processo ensino-aprendizado modifica os autores afirmam que umas das particularidades a serem atenuadas sobre esse aspecto, é justamente a importância do docente dentro desse cenário, ou seja, a sua percepção diante do processo de ser e/ou sentir-se capacitado para essa moderna ferramenta na sua prática profissional.

Schneider et al. (2020) reafirma que as Tecnologias de Informação e Comunicação (TIC) podem ser incluídas e utilizadas no processo de ensino e aprendizagem quer seja na Educação à Distância ou no Ensino Remoto Emergencial (Não Presencial). No cenário atual da pandemia da Covid-19 e a substituição das aulas presenciais pelas aulas remotas, os professores que ainda não sabiam utilizar determinadas tecnologias digitais precisaram aprender e inserir em sua prática docente. Porém, a mudança emergencial do ensino presencial para não presencial vem acompanhado de inúmeros desafios como: o acesso pelos acadêmicos às atividades disponibilizadas, a qualidade das atividades de ensino, as finalidades e objetivos do ensino e da aprendizagem, e a qualificação dos profissionais para o uso dos recursos e meios digitais para o desenvolvimento das aulas, entre outros.

Schleich, Pinto (2021) em seu trabalho demonstrou, sob o ponto de vista de profissionais de educação, a avaliação de uma ferramenta gamificada, de treinamento para docentes em relação a metodologias ativas em educação a distância. Motivada não apenas para que a educação acompanhe o desenvolvimento da tecnologia, mas também pela situação excepcional imposta aos educadores devido à pandemia de COVID-19 e ao consequente isolamento social. Os feedbacks positivos obtidos dos participantes, assim como a alta porcentagem de concluintes e os comentários específicos com os quais eles justificaram a aprovação do curso-jogo, a princípio, indicam que as estratégias de gamificação possuem potencial relevante, como ferramenta, para aumentar o engajamento e diminuir as altas taxas de evasão, especialmente quando utilizadas de forma adequada ao público que se pretende atingir.

Espíndola,Nóbrega,Ramos (2020) apresentou o relato de experiência no qual uma equipe de trabalho coordenada pelo Núcleo de Formação ofereceu um curso baseado na necessidade de uma formação docente voltada para as especificidades das disciplinas da graduação em questão, apresentando possibilidades tecnológicas para o ensino destes conteúdos e suas metodologias, pois muitas vezes os professores envolvidos no curso não vislumbravam as potencialidades pedagógicas das Tecnologias Digitais de Informação e Comunicação (TDIC) apresentadas de forma genérica nas formações anteriormente realizadas. Os autores acreditam que esta iniciativa se configurou um processo de construção contínua, onde os docentes podem construir uma visão sobre o uso das TDIC e integrá-las em suas práticas, de acordo com seus conhecimentos tecnológicos, pedagógicos e de conteúdo e com as particularidades do contexto educativo. A experimentação ofereceu aos professores a possibilidade de construção de seus próprios materiais e atividades educativas, a partir de suas necessidades reais

O trabalho realizado por Diniz, Silva (2020) sinaliza que as desigualdades sociais regionais do Brasil estão diretamente relacionadas à falta de autonomia do aluno para aprendizagem pelas TICs, além da ausência de qualificação profissional do professor para utilizar recursos digitais. Trouxe a experiência realizada pela UFT com a proposta de manter contato, acolhimento e ações que visam efetivar o processo de formação docente de modo remoto on-line e observou que está condicionada a limitações de ordem tecnológica e de um contexto social inédito e ainda enigmático. Entre os desafios, 
professores e alunos tentando um aprendizado rápido e imperfeito com o uso de novas TICs. Como condição geral da sociedade brasileira e também específica da realidade no norte do Tocantins, o mais agravante é que a maioria dos estudantes não dispõe de recursos necessários para o acompanhamento de atividades on-line.

A experiência de professoras que atuam em cursos de licenciatura e bacharelado, em instituições de ensino superior localizadas no estado de Alagoas (Ferreira et al. 2020) coloca em reflexão que o contexto da pandemia tem sido visto como uma lupa para a identificação das mazelas encontradas na sociedade. No caso da educação, vários pontos têm se mostrado frágeis, como a incorporação para o uso das tecnologias digitais na formação continuada dos professores que atuam na educação superior, necessitando de inseridas nos espaços educacionais, no entanto, nota-se que as formações para o uso, quando existente, têm ocorrido de forma majoritariamente instrumental. Desta forma, a atuação do professor neste momento de transição do ensino presencial para o ensino remoto emergencial e a falta de formação continuada desse profissional impacta nos dilemas contemporâneos do uso obrigatório e urgente das interfaces digitais, em caráter instrumentalista, a fim de manter os vínculos entre docentes e discentes e dar continuidade ao calendário letivo nas instituições.

Em oposição ao cenário encontrado no estudo realizado em Tocantins e em Alagoas, Schmitt, Bugalho, Kruger (2021) traz as principais estratégias do processo de ensino-aprendizagem, bem como as percepções dos docentes durante o período de isolamento social no contexto da pandemia gerada pela Covid-19 em quatro instituições de ensino superior da região Sul do Brasil e evidenciou-se que para $96 \%$ dos pesquisados, as disciplinas ocorreram de forma remota; $92 \%$ indicam adaptações pedagógicas; e 76\% responderam que a instituição ofereceu capacitações. Dentre as estratégias de ensino utilizadas no período de isolamento social estão: aulas expositivas com apresentação de conteúdo em slides (98\%); exercícios com resolução (90\%); estudo de casos (69\%); e pesquisas/leituras orientadas sobre o conteúdo (52\%). A análise estatística evidencia que os docentes que utilizaram de problematização/casos de ensino, debates e uso de jogos, acreditam ter alcançado os objetivos de ensinoaprendizagem. Na percepção de $54 \%$ dos docentes, as aulas realizadas de forma remota não representam prejuízos no processo de ensino-aprendizagem dos estudantes atingiram os objetivos.

Os artigos apresentados foram realizados em diferentes regiões do país, cada uma com suas particularidades, mas observa-se que a ausência de capacitação e formação continuada para manejo das tecnologias digitais em sala de aula foi um fator comum em todos os trabalhos. As instituições de ensino superior que tinham uma estrutura tecnológica consolidada antes da pandemia tiveram maior facilidade no processo de adaptação.

\section{Considerações Finais}

A gravidade do problema de saúde como a pandemia de COVID-19 fez com que o processo de ensino e aprendizagem passasse por fortes mudanças, com a necessidade de adequação às recomendações das organizações de saúde passando a ser mediado por tecnologias digitais.

Os resultados apresentados mostram que na maioria dos casos não houve um planejamento adequado e capacitação dos docentes para essa transição do ensino presencial para o ensino remoto emergencial. Podemos perceber a capacidade e o compromisso do professor com o fazer pedagógico, pois passou a dedicar mais tempo para desenvolver as competências necessárias para a continuidade do ensino.

Pode-se perceber ainda que apesar dos esforços, o ensino remoto emergencial trouxe implicações negativas no processo de ensino-aprendizagem e para que haja uma boa implementação dessa modalidade é necessário mudanças na IES criando condições de trabalho, acompanhamento para professores e alunos e capacitações para uso de recursos digitais. No entanto, alguns trabalhos demonstram que quando se tem o conhecimento sobre a ferramenta é possível aumentar o engajamento dos alunos nas aulas. 
Considerando a necessidade de aprofundamento de pesquisas sobre a formação de professores para ambientes virtuais e as demandas que o cenário pandêmico trouxe, esperamos contribuir tanto na reflexão crítica acerca da formação continuada de professores do ensino superior como fomentar as discussões da integração das TDIC aos currículos do Ensino Superior presencial na possibilidade que compondo modelos híbridos de ensino atendam à imprevisibilidade do cotidiano.

\section{Referências}

Brasil. Ministério da Educação. Portaria N $\mathrm{N}^{\mathrm{0}}$ 544, de 16 de junho de 2020. Dispõe sobre a substituição das aulas presenciais por aulas em meios digitais, enquanto durar a situação de pandemia do novo coronavírus -Covid-19, e revoga as Portarias MEC n 343 , de 17 de março de 2020 , nº 345 , de 19 de março de 2020, e n 473, de 12 de maio de 2020. Diário Oficial da União, Poder Executivo, Brasília, DF, 17 jun. 2020. Seção: 1, p. 62 .

Bastos, M. D. C., Canavarro, D. D. A., Campos, L. M., Schulz, R. D. S., Santos, J. B. D., \& Santos, C. F. D. (2020). Ensino remoto emergencial na graduação em enfermagem: relato de experiência na covid-19. Revista Mineira de Enfermagem, 24, 1-6.

Barbosa, A. M., Viegas, M. A. S., \& Batista, R. L. N. F. F. (2020). Aulas presenciais em tempos de pandemia: relatos de experiências de professores do nível superior sobre as aulas remotas. Revista Augustus, 25(51), 255-280.

Botelho, L. L. R., de Almeida Cunha, C. C., \& Macedo, M. (2011). O método da revisão integrativa nos estudos organizacionais. Gestão e sociedade, 5(11), 121-136.

Corrêa, G. T., \& Ribeiro, V. M. B. (2013). A formação pedagógica no ensino superior e o papel da pós-graduação stricto sensu. Educação e Pesquisa, 39, 319334.

Diniz, V. L., \& da Silva, R. A. (2020). Formação de professores no período pandêmico:(im) possibilidades de ações e acolhimento no curso de Geografia da UFT/Araguaína. Revista Docência do Ensino Superior, 10, 1-18.

Dosea, G. S., do Rosário, R. W. S., Silva, E. A., Firmino, L. R., Santos Oliveira, A. M. (2020). Métodos ativos de aprendizagem no ensino online: a opinião de universitários durante a pandemia de COVID-19. Interfaces Científicas-Educação, 10(1), 137-148.

Espíndola, M. B., Reses, G.N, \& Ramos, V. F. C. (2020). Formação docente para o ensino superior mediado por Tecnologias Digitais de Informação e Comunicação: uma proposta baseada no modelo do Conhecimento Pedagógico Tecnológico do Conteúdo. Research, Society and Development, 9(7).

Ferreira, D. H. L., Branchi, B. A., \& Sugahara, C. R. (2020). Processo de ensino e aprendizagem no contexto das aulas e atividades remotas no Ensino Superior em tempo da pandemia Covid-19. Revista práxis, 12(1).

Ferreira, L. F. S., Silva, V. M. C. B., da Silva Melo, K. E., \& Peixoto, A. C. B. (2020). Considerações sobre a formação docente para atuar online nos tempos da pandemia de COVID-19. Revista Docência do Ensino Superior, 10(1-20).

Hodges, C. B., Moore, S., Lockee, B. B., Trust, T., \& Bond, M. A. (2020). The difference between emergency remote teaching and online learning.

Galvão, M. C. B., Ricarte, I. L. M., Darsie, C., Forster, A. C., Ferreira, J. B. B., Carneiro, M.,Sampaio, S, S \& Rocha, J. S. Y. (2021). Usos de tecnologias da informação e comunicação no ensino superior em Enfermagem durante a pandemia da COVID-19. Brazilian Journal of Information Science: research trends, 15, e02108-e02108.

Gusso, H. L., Archer, A. B., Luiz, F. B., Sahão, F. T., Luca, G. G. D., Henklain, M. H. O., Panosso, M, G, Kienen, N, Beltramello, O \& Gonçalves, V. M. (2020). Ensino superior em tempos de pandemia: diretrizes à gestão universitária. Educação \& Sociedade, v.41.

Maciel, M. D. A. C., Andreto, L. M., Ferreira, T. C. M., Mongiovi, V. G., Santos, M. C.F, da Silva, S. L., Santos, C, S, Lima Ferreira, L. (2020). Os desafios do uso de metodologias ativas no ensino remoto durante a pandemia do Covid-19 em um curso superior de enfermagem: um relato de experiência. Brazilian Journal of Development, 6(12).

Nonato, E. D. R. S., Sales, M. V. S., \& Cavalcante, T. R. (2021). Cultura digital e recursos pedagógicos digitais: um panorama da docência na Covid-19. Práxis Educacional, 17(45), 1-25.

Paiva, M. R. F., Parente, J. R. F., Brandão, I. R., \& Queiroz, A. H. B. (2016). Metodologias ativas de ensino-aprendizagem: revisão integrativa. SANARERevista de Políticas Públicas, 15(2).

Pereira, A. S., et al. (2018). Metodologia da pesquisa científica. Metodologia da pesquisa científica. UFSM.

Ries, E. F., Rocha, V. M. P., \& da Silva, C. G. L. (2020). Avaliação do ensino remoto de Epidemiologia em uma universidade pública do Sul do Brasil durante pandemia de COVID-19.

Rother, E. T. Revisão sistemática X revisão narrativa. Acta Paulista de enfermagem, 2(2)

Sallaberry, J. D., dos Santos, E. A., Bagatoli, G. C., Lima, P. C. M., \& Bittencourt, B. R. (2020). Desafios docentes em tempos de isolamento social: estudo com professores do curso de Ciências Contábeis. Revista Docência do Ensino Superior, 10, 1-22.

Santos Junior, V. B., \& da Silva Monteiro, J. C. (2020). Educação e covid-19: as tecnologias digitais mediando a aprendizagem em tempos de pandemia. Revista Encantar-Educação, Cultura e Sociedade, 2, 01-15. 
Research, Society and Development, v. 10, n. 12, e43101320800, 2021

(CC BY 4.0) | ISSN 2525-3409 | DOI: http://dx.doi.org/10.33448/rsd-v10i13.20800

Santos, K. D., de Castro, S., do Valle Junior, S. R., Rodrigues, E. S., \& de Almeida, P. R. (2021). Ensino online em tempos de pandemia: a opinião de universitários quanto aos desafios encontrados. Research, Society and Development, 10(10).

Santos, L. M., \& Martins, L. M. (2015). Cibercultura: A Educação no Mundo Contemporâneo. Encontro Internacional de Formação de Professores e Fórum Permanente de Inovação Educacional, 8(1).

Santos, S. R. M., \& Cardim, N. N. (2016). A arte de ensinar no ciberespaço. Research, Society and Development, 1(2), $144-155$.

Schmidt, J. B., Lopes, F. M., \& Pereira, S. L. (2020). Impacto da pandemia no trabalho docente no ensino superior. Monumenta-Revista de Estudos Interdisciplinares, 1(2), 191-213.

Schleich, M. V., \& Pinto, S. A. (2021). Utilização de Treinamento Gamificado para Capacitação de Professores em Ensino a Distância. Revista Brasileira de Aprendizagem Aberta e a Distância, 2(Especial).

Schmitt, D. C., Bugalho, D. K., \& Kruger, S. D. (2021). Percepções docentes e as estratégias de ensino-aprendizagem durante o isolamento social motivado pelo COVID-19. Revista Catarinense da Ciência Contábil, 20, e3133-e3133. 